\title{
Experimental and Theoretical Spectroscopic Investigations of 4-Bromo-3-methylbenzonitrile
}

\author{
SHAJIKUMAR ${ }^{1,2}$ and R. GANAPATHI RAMAN ${ }^{1,2 *}$ \\ 'Department of Physics, Noorul Islam Centre for Higher Education, Kumaracoil - 629 180, \\ Kanyakumari Dist, Tamilnadu, India. \\ ${ }^{2}$ Nano Computational Laboratory, Department of Nano Technology, Noorul Islam Centre \\ for Higher Education, Kumaracoil - 629 180, Kanyakumari Dist, Tamilnadu, India. \\ ${ }^{*}$ Corresponding author E-mail: ganapathiraman83@gmail.com \\ http://dx.doi.org/10.13005/ojc/340338
}

(Received: May 05, 2017; Accepted: April 10, 2018)

\section{ABSTRACT}

\begin{abstract}
4-Bromo-3-methylbenzonitrile (4B3MBN) was investigated by electronic structure calculations based on Density Functional Theory (DFT) carried out at HF methods. The FTIR $\left(400-4000 \mathrm{~cm}^{-1}\right)$ and FT-Raman $\left(50-3500 \mathrm{~cm}^{-1}\right)$ spectra of $4 B 3 M B N$ had been traced in the solid phase. The equilibrium geometrical parameters and vibrational assignments of 4B3MBN for the ground state had been deliberated through the theoretical methods invoking a basis set. The charges are computed by MA with same basic sets tabulated. The visual representations are the mostly welcomed one compared with other studies. Finally, spectra of the title compound have good complement while compared with the calculation results were applied to simulate infrared and Raman spectra.
\end{abstract}

Keywords: 4B3MBN, Density functional theory, VEDA, TED.

\section{INTRODUCTION}

The many organic molecules investigated for future applications through the experimental as well as the theoretical methods in the various twigs of the science and engineering ${ }^{1}$. The theoretical methods have the fast and furious results for the larger molecules to evaluate the applications in addition to their physicochemical properties. The computational techniques powerful tool for the pin pointed answers for the molecules, So as to corroborate and yet expand the experimental results. Benzonitrile is the child molecule to the parent molecule ammonia to toluene, which had the enormous changing with the consequence of the particular ratio ${ }^{1}$. Benzonitrile has the nick names like phenyl cyanide or cyanobenzone; these are very sensitive in air, skin and eye nuisance. The fragrances, cosmetics, steroid, aromatic alcohols for color removers, solvents for fatty acids, hydrocarbons and oils are used with benzonitrile as a chemical broker. The existence of Vitamin B-complex in plants and animal tissues helps to increase the salicylate level in blood. This complex is used in cholocystrographic tests, urology media, miticides and medicine productions ${ }^{2}$. 
Benzonitrile compound is the best solvent in the chemical and physical laboratories. Because of benzene has an aprotic polar molecule with a dipole moment of 4.18Debye. The properties enhanced while added the substituted roles to the benzene. The substitution benzonitrile compounds had weak effect and strong inhibitory effect as a consequence of its position. The catalytic rate of the nitrilase enzyme is the vast cause for the weak effect in the meta or para position of benzonitrile. In the ortho position of the benzonitrile has strong effect due to steric hindrance ${ }^{3}$. Benzonitrile is used as antiseptic, anti-urinary, pharmaceutical, agrochemical intermediates, epoxy curing agent and dye sensitizers etc.

The title compound $4 \mathrm{~B} 3 \mathrm{MBN}$ is almost planar and the derivatives are used like midways in the production of phthalocyanine dyes. The surrogated phthalocyanine dyes are used for DSSC, photo redox responses and photodynamic cancer therapy ${ }^{4}$. To the best of our knowledge, the vibrational assignments and other properties never determined for this compound still now. So this article going to serve about complete vibrational assignments of different modes of molecules. and electronic and thermo studies are simultaneously take over to the molecule.

\section{RESULTS AND DISCUSSIONS}

\section{Optimized geometry}

The B3LYP/6311++G(d,p) energy values are most probable global minimum energy and good agreement with experiment data ${ }^{5}$. Table. 3.1 shows the equilibrium geometry parameters of the 4B3MBN molecule for two dissimilar basis sets. Fig. 3.1 shows the computerized.

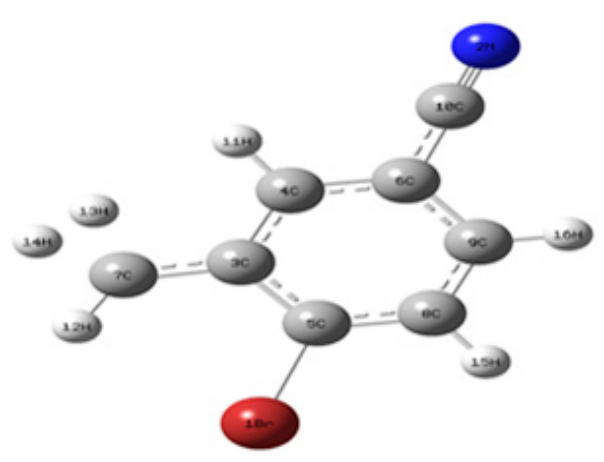

Fig. 1. Optimized Structure of 4B3MBN
Structure of the 4B3MBN molecule with same basis set. The length should be increased between every atom in the calculated values while compared with experimental values because of substituent of the title molecule. The length and angle of the $\mathrm{Br}$ substituent are longer value $1.91 \AA$ in all other compounds. Carbon interactions are short value in the whole molecule. These effects are qualified for the intra charge transformations (ICT) for stability of the molecule.

\section{Vibrational assignments}

There are 41 vibrational assignments are assigns for the $4 \mathrm{~B} 3 \mathrm{MBN}$ molecule. In the 42 assignments $\mathrm{C} 1$ point group symmetry includes the 30 in-plane $(\beta)$ and 12 out-of-plane $(\gamma)$ bending vibrations. The experimental and calculated graphical representations of both spectra (FTIR \& FTR) are illustrated in the Fig. 3.3 and Fig. 3.4. The molecule vibrational modes have been separated by 16 stretching $(v), 13$ bending, 13 torsion $(\tau)$ and 18 $\mathrm{CH}$ modes are tabulates in Table.3.3.

\section{$\mathrm{CH}$ vibrations}

Four kinds of $\mathrm{CH}$ moieties are calculated in the title compound 4B3MBN. In this $\mathrm{CH}$ moieties have been listed, six $\cup \mathrm{CH}$ and $\beta \mathrm{CH}$ as well as three torsion and $\delta$ bending vibrations. The scenery of the substituent does not align because of these stretching vibrations. The stretching has most feasible frequency between the region at $3100-3000 \mathrm{~cm}^{16,7}$. The calculated stretching vibrations of the title compound region, in between $3301-2431 \mathrm{~cm}^{1}$. The experimental frequencies have been observed at the regions 1698 , $2319 \mathrm{~cm}^{1}$. The $\mathrm{CH}$ stretching and $\beta$ bending vibrations are incorporate with each other. The calculated $\mathrm{CH} \beta$ bending vibrations of $4 \mathrm{~B} 3 \mathrm{MBN}$ occurs in the region of $1233-1017 \mathrm{~cm}^{1}$ and observed FTIR and FTR spectra at $1023 \mathrm{~cm}^{1}$ and $1040 \mathrm{~cm}^{1}$, respectively. The $\mathrm{CH} \delta$ bending transpires at the region $950-800 \mathrm{~cm}^{1}$ generally. The analyzed $\delta$ bending vibrations of $4 \mathrm{~B} 3 \mathrm{MBN}$ are found at $815,941,965 \mathrm{~cm}^{1}$ and observed in FTIR arises in the region $811,888 \mathrm{~cm}^{1}$. In this case, the $\delta$ bending has been merged with the torsion vibrations. Calculate and observed values good agreement with each other.

\section{CBr vibrations}

$\mathrm{CBr}$ moieties tabulated on the root of calculated energy distribution and separated three 
kinds of styles. Two stretching and three in-plane bending vibrations are packed in the $\mathrm{CBr}$ atom. In the literature survey, the authors assigned vibrations frequency range of $1129-480 \mathrm{~cm}^{1}$ while the Carbon interactions with others heavy atoms like $\mathrm{Cl}, \mathrm{Br}, \mathrm{I}^{8}$. The 4B3MBN compound has the strong stretching vibrations in the region of 254, 522 and $1040 \mathrm{~cm}^{1}$ found from Raman spectrum. Bending vibrations in the FTR spectra occurs in the range of 134 , $380 \mathrm{~cm}^{1}$ and the calculated frequency of the title molecule transpire in the range at $135,219,361 \mathrm{~cm}^{1}$. These vibrations are very well agreed with literature survey ${ }^{9}$.

\section{CN vibrations}

In the CN moieties, stretching frequency is the intensively localized one due to the TED for this frequency contains good contribution from that constant value of stretching force. The benzonitrile compound wavenumbers of stretching vibrations fall in the range $2220-2240 \mathrm{~cm}^{1}{ }^{10}$. IR intensity modulated depends upon add the substituent to the benzonitrile. In this research compound has been identified at 2338 and $2217 \mathrm{~cm}^{1}$ in Raman and FTIR spectra respectively. The calculated wavenumbers of stretching vibrations at $2331 \mathrm{~cm}^{1}$ coincide with the Raman value. This is the ideal frequency of the whole molecule which confirmed the $\mathrm{CN}$ stretching with $89 \%$ assignment. The bending vibrations $(\beta)$ of the title molecule spotted at 134, $380,548 \mathrm{~cm}^{1}$ in Raman spectra. These experiment values are well agreement with the calculated frequencies.

CC vibrations

There are six equivalents and two out of CC bonding in the 4 B3MBN compound and totally eight $\mathrm{CC}$ stretching vibrations exist. Generally, the benzene ring uCC vibrational modes fall in the constituency $1650-1200 \mathrm{~cm}^{1}{ }^{11}$. The title compound vCC vibrations are found in the regions at 1203 , 1375, 1428, 1459, 1541, 1648, $2217 \mathrm{~cm}^{1}$ and 712, 1040, 1250, 1374, 1416, $1612 \mathrm{~cm}^{1}(735,965,1022$, 1141, 1170, 1209, 1283, 1315, 1343, 1411, 1492, $1569,1612,2331 \mathrm{~cm}^{1}$ by theoretically) through IR \& Raman spectra, correspondingly. In addition, some other modes are couples with CC bending vibrations $(\beta)$ are found in the regions at $1023 \mathrm{~cm}^{1}$ and $2217 \mathrm{~cm}^{1}\left(1022,2231 \mathrm{~cm}^{1}\right.$ by theoretically) through spectra respectively.

\section{CCCC torsional vibrations}

The ring torsions have been assigned in the region at below $800 \mathrm{~cm}^{-1}$ which is discussed in present paper referred by earlier reports ${ }^{12}$. The IR and Raman spectra peak observe in the regions at 578, $627 \mathrm{~cm}^{1}$ and 496, $572 \mathrm{~cm}^{-1}$, respectively. These peaks have been calculated at the region at $73,144,208,277,402,472,580,648 \mathrm{~cm}^{-1}$ by B3LYP methods which are well merge with observed values. And these wavenumbers are mixed with CCCN torsions in the investigated molecules.

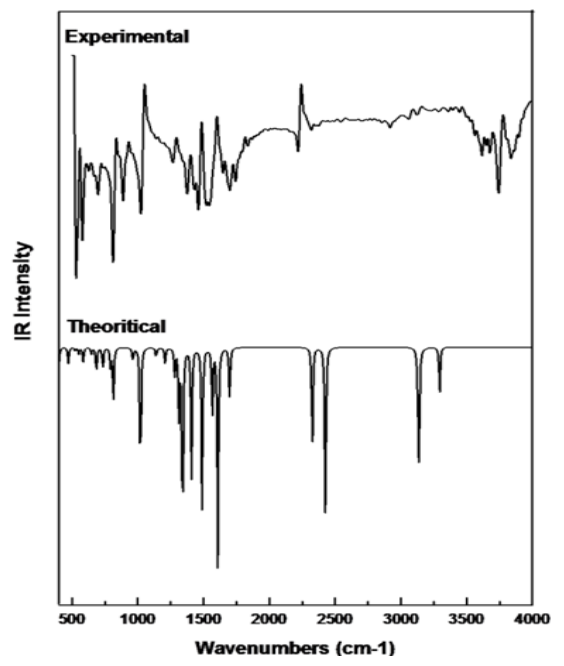

Fig. 2. FTIR spectrum of $4 B 3 M B N$

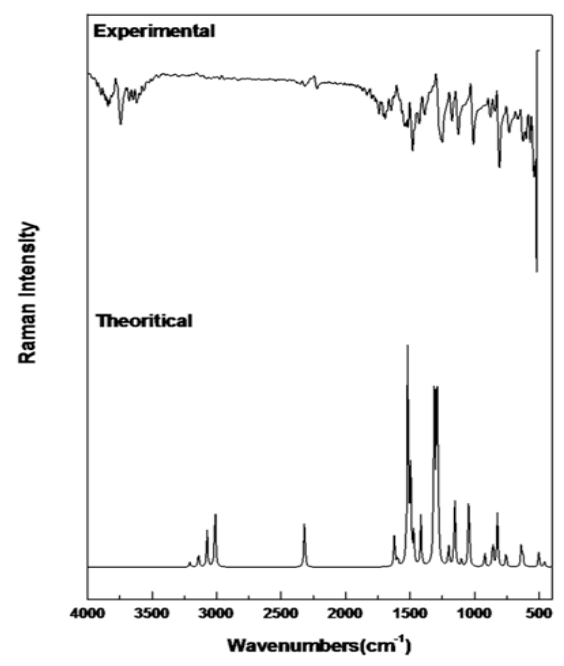

Fig. 3. FTR spectrum of 4B3MBN

\section{Molecular electrostatic potential}

The visual representations are the mostly welcomed one compared with other studies. Molecular electrostatic potential (MEP) is the versatile used visual illustration for find out the reactivity of the molecule which explains through 
its colors ${ }^{13}$, hydrogen bonding interactions and biological detection methods ${ }^{14}$. The electrophilic and nucleophilic attacks are demonstrated by two different colors. The MEP's of 4B3MBN calculated
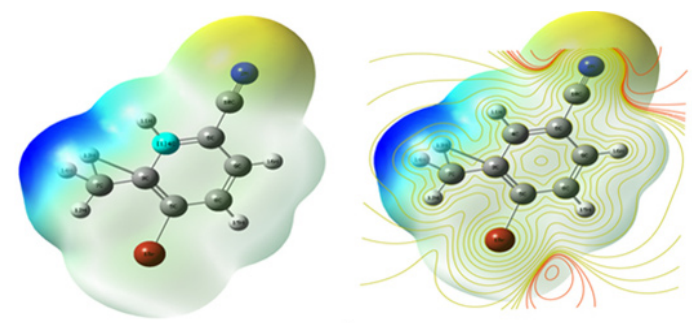

Fig. 3. Electrostatic Potential map and counter map of $4 B 3 M B N$ and drawn by the computational method in Fig. 3.6. The colors are increased the order of red, yellow, green, blue. The red color starts from negative region for electrophilic reactivity and blue ends with positive region for nucleophilic reactivity regions. The values of the regions increased from red to blue (-9.944 to 9.944) for the title molecule. The carbon, nitrogen and Bromine groups are almost negative electrostatic potential for electrophilic attack. The hydrogen atoms are the positive one for nucleophilic attack. The Mulliken population analysis is showing the electronic charges distribution of the molecules which identified the support of MEP maps.

Table 1: Geometrical Parameters of 4B3MBN

\begin{tabular}{|c|c|c|c|c|c|c|c|}
\hline Bond Length & B3LYP & Exp. & Bond Angle & B3LYP & Exp. & Dihedral Angle & B3LYP \\
\hline $\mathrm{Br} 1-\mathrm{C} 5$ & 1.91 & 1.882 & C4-C3-C5 & 120 & 121 & C5-C3-C4-C6 & 0 \\
\hline N2-C10 & 1.1466 & 1.133 & C4-C3-C7 & 120 & 120.8 & C5-C3-C4-H11 & 180 \\
\hline C3-C4 & 1.54 & 1.503 & C4-C3-H13 & 76.55 & & C7-C3-C4-C6 & 180 \\
\hline C3-C5 & 1.3552 & 1.371 & C5-C3-C7 & 120 & & C7-C3-C4-H11 & 0 \\
\hline C3-C7 & 1.54 & 1.503 & C5-C3-H13 & 163.45 & & H13-C3-C4-C6 & 180 \\
\hline $\mathrm{C} 3-\mathrm{H} 13$ & 1.2703 & & C3-C4-C6 & 120 & 120.8 & $\mathrm{H} 13-\mathrm{C} 3-\mathrm{C} 4-\mathrm{H} 11$ & 0 \\
\hline C4-C6 & 1.3552 & 1.371 & C3-C4-H11 & 120 & 119.9 & C4-C3-C5-Br1 & 180 \\
\hline $\mathrm{C} 4-\mathrm{H} 11$ & 1.07 & 0.96 & C6-C4-H11 & 120 & 119.9 & C4-C3-C5-C8 & 0 \\
\hline $\mathrm{C5}-\mathrm{C} 8$ & 1.54 & 1.503 & $\mathrm{Br} 1-\mathrm{C} 5-\mathrm{C} 3$ & 120 & 119.6 & C7-C3-C5-Br1 & 0 \\
\hline C6-C9 & 1.54 & 1.503 & $\mathrm{Br} 1-\mathrm{C} 5-\mathrm{C} 8$ & 120 & 119.6 & C7-C3-C5-C8 & 180 \\
\hline C6-C10 & 1.54 & 1.503 & C3-C5-C8 & 120 & 118.6 & $\mathrm{H} 13-\mathrm{C} 3-\mathrm{C} 5-\mathrm{Br} 1$ & 0 \\
\hline $\mathrm{C} 7-\mathrm{H} 12$ & 1.07 & 0.96 & C4-C6-C9 & 120 & 121.8 & H13-C3-C5-C8 & 180 \\
\hline $\mathrm{C} 7-\mathrm{H} 13$ & 1.07 & 0.96 & C4-C6-C10 & 120 & 119.6 & C4-C3-C7-H12 & 180 \\
\hline $\mathrm{C} 7-\mathrm{H} 14$ & 1.07 & 0.96 & C9-C6-C10 & 120 & 120.3 & C4-C3-C7-H14 & 0 \\
\hline C8-C9 & 1.3552 & 1.371 & C3-C7-H12 & 90 & 109.5 & C5-C3-C7-H12 & 0 \\
\hline $\mathrm{C} 8-\mathrm{H} 15$ & 1.07 & 0.93 & C3-C7-H14 & 144.74 & & C5-C3-C7-H14 & 180 \\
\hline \multirow[t]{16}{*}{$\mathrm{C} 9-\mathrm{H} 16$} & 1.07 & 0.93 & $\mathrm{H} 12-\mathrm{C} 7-\mathrm{H} 13$ & 144.74 & & C3-C4-C6-C9 & 0 \\
\hline & & & $\mathrm{H} 12-\mathrm{C} 7-\mathrm{H} 14$ & 125.26 & & C3-C4-C6-C10 & 180 \\
\hline & & & $\mathrm{H} 13-\mathrm{C} 7-\mathrm{H} 14$ & 90 & 109.5 & $\mathrm{H} 11-\mathrm{C} 4-\mathrm{C} 6-\mathrm{C} 9$ & 180 \\
\hline & & & C5-C8-C9 & 120 & 119.9 & $\mathrm{H} 11-\mathrm{C} 4-\mathrm{C} 6-\mathrm{C} 10$ & 0 \\
\hline & & & C5-C8-H15 & 120 & 119.9 & $\mathrm{Br} 1-\mathrm{C} 5-\mathrm{C} 8-\mathrm{C} 9$ & 180 \\
\hline & & & C9-C8-H15 & 120 & 119.9 & $\mathrm{Br} 1-\mathrm{C} 5-\mathrm{C} 8-\mathrm{H} 15$ & 0 \\
\hline & & & C6-C9-C8 & 120 & & C3-C5-C8-C9 & 0 \\
\hline & & & C6-C9-H16 & 120 & 119.9 & C3-C5-C8-H15 & 180 \\
\hline & & & C8-C9-H16 & 120 & 119.9 & C4-C6-C9-C8 & 0 \\
\hline & & & & & & C4-C6-C9-H16 & 180 \\
\hline & & & & & & C10-C6-C9-C8 & 180 \\
\hline & & & & & & C10-C6-C9-H16 & 0 \\
\hline & & & & & & C5-C8-C9-C6 & 0 \\
\hline & & & & & & C5-C8-C9-H16 & 180 \\
\hline & & & & & & H15-C8-C9-C6 & 180 \\
\hline & & & & & & $\mathrm{H} 15-\mathrm{C} 8-\mathrm{C} 9-\mathrm{H} 16$ & 0 \\
\hline
\end{tabular}


Table 2: Vibrational assignments for 4B3MBN

\begin{tabular}{|c|c|c|c|c|c|c|c|}
\hline \multirow{2}{*}{$\begin{array}{l}\text { Normal } \\
\text { Modes } \\
\text { Mode }\end{array}$} & \multicolumn{3}{|c|}{ Experimental $\left(\mathrm{cm}^{-1}\right)$} & \multicolumn{3}{|c|}{ Scaled Wavenumbers $\left(\mathrm{cm}^{-1}\right)$} & \multirow[b]{2}{*}{$\begin{array}{l}\text { Vibrational } \\
\text { assignments }\end{array}$} \\
\hline & Label & FT-IR & FT-Raman & B3LYP & $\begin{array}{c}\text { IR } \\
\text { Intensity } \\
(\mathrm{Km} / \mathrm{mol})\end{array}$ & $\begin{array}{l}\text { Raman } \\
\text { Intensity }\end{array}$ & \\
\hline 1 & $A^{\prime \prime}$ & & & -2252 & 0.246 & 303.223 & $\delta \mathrm{CHCH}(99)$ \\
\hline 2 & $A^{\prime \prime}$ & & & -613 & 257.277 & 473.250 & $\delta \mathrm{CHCH}(84)+\tau \mathrm{HCCC}(13)$ \\
\hline 3 & $A^{\prime \prime}$ & & & 73 & 4.238 & 9407.325 & $\tau \operatorname{CCCC}(41)+\tau \operatorname{CcC} \beta r(35)$ \\
\hline 4 & $A^{\prime}$ & & 134 & 135 & 6.947 & 9062.251 & $\beta \operatorname{CCC}(46)+\beta \operatorname{CCN}(38)+\beta \operatorname{CC} \beta r(11)$ \\
\hline 5 & $A^{\prime}$ & & & 144 & 4.597 & 818.871 & $\tau \operatorname{CCCC}(60)+\tau \operatorname{HCCC}(17)$ \\
\hline 6 & $A^{\prime \prime}$ & & & 208 & 10.281 & 414.616 & $\tau \operatorname{CCC} \beta r(28)+\tau \operatorname{HCCC}(26)+\tau \operatorname{CCCC}(19)$ \\
\hline 7 & $A^{\prime}$ & & & 219 & 7.462 & 3594.329 & $\beta \operatorname{CC} \beta r(62)+\beta \operatorname{CCC}(23)$ \\
\hline 8 & $A^{\prime}$ & & 254 & 266 & 0.919 & 3760.133 & $\cup \beta \operatorname{rC}(46)+\beta \operatorname{CCC}(28)$ \\
\hline 9 & $A^{\prime \prime}$ & & & 277 & 3.120 & 93.043 & $\tau \mathrm{HCCC}(40)+\tau \operatorname{CCC} \beta r(22)+\tau \operatorname{CCCC}(13)$ \\
\hline 10 & $A^{\prime}$ & & 380 & 361 & 16.581 & 1306.858 & $\beta C C C(44)+\beta \operatorname{CCN}(12)+\beta \operatorname{HCC}(12)+\beta C \operatorname{CC} \beta r(10)$ \\
\hline 11 & $A^{\prime \prime}$ & & & 402 & 10.840 & 59.070 & $\tau \operatorname{CccC}(72)+\tau \operatorname{CcCN}(10)$ \\
\hline 12 & $A^{\prime \prime}$ & & 496 & 472 & 9.471 & 506.472 & $\tau \operatorname{CcCC}(54)+\tau \operatorname{CcCN}(31)+\tau \operatorname{CCC} \beta r(11)$ \\
\hline 13 & $A^{\prime}$ & & 522 & 525 & 2.798 & 240.879 & $\beta \operatorname{CCC}(35)+v \operatorname{CC}(22)+v \beta r C(18)$ \\
\hline 14 & $A^{\prime}$ & & 548 & 553 & 3.841 & 1931.634 & $\beta \operatorname{CCC}(43)+\beta \operatorname{CCN}(12)$ \\
\hline 15 & $A^{\prime \prime}$ & 578 & 572 & 580 & 1.482 & 19.100 & $\tau \operatorname{CccC}(77)+\tau \operatorname{CcCN}(15)$ \\
\hline 16 & $A^{\prime}$ & & & 587 & 8.496 & 302.955 & $\beta \operatorname{CCC}(31)+\beta \operatorname{CCN}(28)$ \\
\hline 17 & $A^{\prime \prime}$ & 627 & & 648 & 4.103 & 239.624 & $\tau \operatorname{CccC}(67)+\tau \operatorname{CcCN}(14)$ \\
\hline 18 & $A^{\prime}$ & 697 & & 686 & 17.909 & 694.714 & $\beta \mathrm{HCC}(42)+\beta \operatorname{CCC}(38)$ \\
\hline 19 & $A^{\prime}$ & & 712 & 735 & 13.119 & 1733.726 & $\beta \operatorname{CCC}(31)+v \operatorname{CC}(13)$ \\
\hline 20 & $A^{\prime \prime}$ & & & 794 & 10.720 & 16.150 & $\tau \mathrm{HCCC}(55)+\delta \mathrm{CCCH}(20)+\tau \mathrm{HCCH}(17)$ \\
\hline 21 & $A^{\prime \prime}$ & 811 & & 815 & 37.046 & 80.179 & $\delta \mathrm{CCCH}(70)+\tau \mathrm{HCCC}(12)$ \\
\hline 22 & $A^{\prime \prime}$ & 888 & & 941 & 0.242 & 19.861 & $\tau \mathrm{HCCH}(72)+\tau \mathrm{HCCC}(19)$ \\
\hline 23 & $A^{\prime}$ & & & 965 & 8.577 & 280.184 & vCC $(57)$ \\
\hline 24 & $A^{\prime}$ & 1023 & 1040 & 1022 & 86.113 & 1197.028 & $\beta \operatorname{CCC}(47)+v C C(26)+v \beta r C(10)$ \\
\hline 25 & $A^{\prime}$ & & & 1141 & 6.624 & 10.146 & $\beta \mathrm{HCC}(39)+v \mathrm{CC}(16)$ \\
\hline 26 & $A^{\prime}$ & & & 1170 & 0.274 & 191.564 & $\beta \mathrm{HCC}(56)+v \mathrm{CC}(16)$ \\
\hline 27 & $A^{\prime}$ & & 1250 & 1209 & 9.482 & 1596.052 & $\beta \mathrm{HCC}(32)+v \mathrm{CC}(22)$ \\
\hline 28 & $A^{\prime}$ & 1266 & & 1283 & 15.357 & 281.706 & $\beta \mathrm{HCC}(51)+v \mathrm{CC}(21)$ \\
\hline 29 & $A^{\prime}$ & & & 1315 & 39.844 & 201.944 & vCC(73) \\
\hline 30 & $A^{\prime}$ & 1375 & 1374 & 1343 & 126.961 & 499.217 & $\beta \mathrm{HCC}(45)+v C C(24)$ \\
\hline 31 & $A^{\prime}$ & 1428 & 1416 & 1411 & 75.293 & 152.166 & $v \mathrm{CC}(53)+\beta \mathrm{HCC}(16)$ \\
\hline 32 & $A^{\prime}$ & 1459 & & 1492 & 95.942 & 199.388 & $v \mathrm{CC}(46)+\beta \mathrm{HCC}(36)$ \\
\hline 33 & $A^{\prime}$ & 1541 & & 1569 & 41.204 & 789.702 & $v C C(53)+\beta \mathrm{HCC}(16)$ \\
\hline 34 & $A^{\prime}$ & 1648 & 1612 & 1612 & 131.186 & 1422.424 & $v \mathrm{CC}(52)+\beta \mathrm{HCC}(12)$ \\
\hline 35 & $A^{\prime}$ & 1698 & & 1701 & 32.549 & 172.222 & $v \mathrm{CH}(55)+\beta \mathrm{HCH}(32)$ \\
\hline 36 & $A^{\prime}$ & 2217 & 2338 & 2331 & 62.212 & 3298.040 & uNC(89)+uCC(11) \\
\hline 37 & $A^{\prime}$ & 2319 & & 2431 & 108.420 & 137.357 & vCH(95) \\
\hline 38 & $A^{\prime}$ & & & 3135 & 21.637 & 533.274 & $v \mathrm{CH}(68)+\beta \mathrm{HCH}(19)$ \\
\hline 39 & $A^{\prime}$ & & & 3145 & 72.690 & 215.473 & $v \mathrm{CH}(24)+\beta \mathrm{HCH}(24)$ \\
\hline 40 & $A^{\prime}$ & & & 3195 & 0.526 & 98.421 & vCH(99) \\
\hline 41 & $A^{\prime}$ & & & 3215 & 0.121 & 244.687 & vCH(99) \\
\hline 42 & $A^{\prime}$ & & & 3301 & 29.107 & 23.606 & $v \mathrm{CH}(80)+\beta \mathrm{HCH}(11)$ \\
\hline
\end{tabular}

v-stretching; $\beta$-in plane bending; $\delta$-Out-Of-plane bending; $\tau$ - torsion; TED-Total Energy Distribution 


\section{CONCLUSION}

The 4B3MBN molecule has been observed FTIR and FTR spectra for experimental studies. The theoretical calculations are performed for the B3LYP/6-311++G (d, p) and (2d, p) method. These basis sets were the best and minimum energy values compared with others. The vibrational assignments with TED \% has been predicted and analyzes the vibrational studies. Both experimental and theoretical studies were compared and tabulated. MEP map drawn and explained the different charges and interactions of the molecules. The optimized parameters are the great impact for the above all. These properties show that the title compound 4B3MBN had good chemical stability and bioactivities are helping the future researchers and innovative thinkers.

\section{REFERENCES}

1. Ajaypraveenkumar, A.; Raman, R. G. J. Chem. Pharm. Sci., 2017, 27-41.

2. El-Azab, A.S.; Jalaja, K.; Abdel-Aziz, A.M.; Al-Obaid, A.M.; Mary, Y.S.; Panicker, C.Y.; Alsenoy, C.V. J. Mol. Struct., 2016, 1119, 451-461.

3. Sudha, S.; Sundaraganesan, N.; Kurt, M.; Cinar, M.; Karabacak, M. J. Mol. Struct., 2011, 985, 148-156.

4. Ajaypraveenkumar, A.; Raman, R. G. J. Chem. Pharm. Sci., 2017, 1-9.

5. Dai, S.; Weng, J.; Sui, Y.; Chen, S.; Xiao, S.; Huang, Y.; Kong, F.; Pan, X.; Hu, L.; Zhang, C.; Wang, K. Inorg. Chim. Acta., 2008, 361, 786-791.

6. Govindharaju, R.; Balasubramaniyan, S.; Rajasekar, K.; Ramachandramoorthy, T. Int. J. Pharm. Res. Rev., 2014, 3(10), 8-13.

7. Remya.; Karunakaran.; Cherumuttathu H.S. J. Comput. Chem., 2014, 35(12), 910-922.
8. Ajaypraveenkumar, A.; Raman, R. G. J. Chem. Pharm. Sci., 2017, 10, 1309-1316.

9. Saravanan, R.R.; Seshadri, S.; Gunasekaran, S.; Mendoza-Merono, R.; Garcia-Granda, S. Spectrochim. Acta., Part A. 2015, 139, 321-328.

10. Parr, R.R.; Yang, R.G. Density Functional Theory of Atoms and Molecules, Oxford University Press, New York, USA, 1989.

11. Anbarasan, P.M.; Subramanian, M.K.; Manimegala, S.; Suguna, K.; Ilangovan, V.; Sundaraganesan, N. J. Chem. Pharm. Res. 2011, 3(3), 123-136.

12. Shajikumar:; Ajaypraveenkumar, A.; Raman, R. G. J. Chem. Pharm. Sci., 2017, 2063-2072.

13. Murugan, M.; Balachandran, V.; Karnan, M. J. Chem. Pharm. Res., 2012, 4(7), 3400-3413.

14. Ajaypraveenkumar, A.; Raman, R.G.: Sebastian, S. Recent Trends in Materials Science and Applications. 2017, 189, 629-654. 